\title{
Study on Synergistic Mechanism of Water Environment Governance in Dongting Lake Basin Based on Evolutionary Game
}

\author{
Mao Chai ${ }^{1}$, Yalan Deng ${ }^{2 *}$, Muhammad Tayyab Sohail ${ }^{1}$ \\ ${ }^{1}$ School of Public Administration, Xiangtan University Xiangtan, Hunan P.R. China \\ ${ }^{2}$ School of Public Administration, Central South University Changsha, Hunan P.R. China
}

\begin{abstract}
Watershed water environment governance has always been a research hotspot in the field of transboundary governance. Based on evolutionary game theory, the regional governments of East Dongting Lake, West Dongting Lake and South Dongting Lake were taken as participants to construct a tripartite game model, and the game evolution strategies under unconstrained and constrained conditions were explored respectively, so as to analyze the influencing factors of the construction of synergistic mechanism of water environment governance in Dongting Lake Basin. The results show that: (1) Under the unconstrained condition, the stable strategy of the evolutionary game is "two parties govern, one party does not govern". However, without intervention of external restraint measures for a long time, the players keep learning and improving according to the game results, and the final synergy mechanism cannot be achieved. (2) Under constraint conditions, the composition of synergistic mechanism mainly depends on the size of ecological compensation and punishment given by the superior government and the duration of constraint by the superior government.
\end{abstract}

\section{Introduction}

Dongting Lake is mainly located in the northern part of Hunan Province, straddling Hunan and Hubei provinces. In terms of economic benefit, Dongting Lake District is an important production base of commodity grain, freshwater fish, cotton and flax in China. On July 31, 2017, the Sixth Central Environmental Protection Supervision Group reported to the Hunan Provincial Government that the water quality of Dongting Lake has deteriorated seriously in the past three years. The State and Hunan Provincial Party Committee attach great importance to the water environment management of Dongting Lake Basin. The People's Government of Hunan Province issued the Implementation Plan of the Comprehensive Management of the Water Environment of Dongting Lake in Hunan Province (2018-2025) to strengthen the guidance on the comprehensive management of the water environment of Dongting Lake. Many researches gave importance to this problem, Yang Mengjie et al. [1], based on the game theory, introduced external drive and internal equilibrium, and discussed the cooperation mechanism to balance the interest conflicts between the upper and lower reaches of the Taipu River and to encourage the upper and lower reaches to realize cooperation protection. Another researcher [2] took the analysis object and used game theory to sort out possible game situations within the basin and explored the construction of basin coordination mechanism. Mahjouri et al. [3] studied the allocation of high-quality water resources across basins from the perspective of game theory through the optimal model of resource allocation, and established the economic coordination model and environmental standards for water resources management across basins. In terms of exploring the mechanism of ecological compensation, $\mathrm{Li}$ Ning et al. [4] used game theory to analyze the decisionmaking behavior of compensation stakeholders and found that a balanced strategy could not be reached without central intervention. Taking the Lijiang River Basin as an example, Hu Zhenhua et al. [5] calculated the amount of ecological compensation based on the evolutionary game and the actual situation of the Lijiang River Basin. Yang Guangming et al. [6] built a game model of ecological compensation behavior between the government and the central government in the upper and lower reaches of the Three Gorges Basin, and analyzed the interest demands and compensation behaviors among the three. In terms of institutional construction, Ding Shejiao [7] explored solutions to the "institutional incentive paradox" of river pollution control from the perspectives of alternative strategy sets, income structure and information structure of all parties in the game. Based on game theory, Li Sheng [8] analyzed the inter-administrative watershed water pollution control system, aiming to provide rules and suggestions for improving the water environment quality of the watershed. In terms of government regulation, 
Zhang Jun et al. [9] explored and analyzed the government's regulatory measures in river basin pollution control by establishing a game model between pollution source enterprises and the government. In terms of costsharing research, Lai Ping et al. [10], based on cooperative game theory, built a game model for cost-sharing of watershed water pollution governance, and innovatively used binomial half-value solution to solve the problem. Shi et al. [11] proposed a cost model for emission reduction of transboundary pollutants in basins. The fluidity of the river basin will make the pollution of one administrative area spread to the adjacent administrative area, and produce negative externality effect. The systematization of the environment will cause the environmental damage in one administrative area to have a knock-on effect and lead to the ecological damage in neighboring administrative areas. On the contrary, the improvement of watershed environment governance will also produce positive external effects. When facing the problem of river basin water environment governance, the main players of the game, based on the attribute of economic man, tend to make behavioral choices and make decisions of governance or not based on the maximization of their own economic benefits. The main factors affecting the water quality of West Dongting Lake are agricultural non-point source pollution, suspended sediment and point source pollution of heavy metals. Due to the sustainable economic development of South Dongting. Based on evolutionary game, local governments in the east, west and south Dongting Lake regions constructed tripartite game models for $G_{1}, G_{2}$ and $G_{3}$, respectively, to explore the construction of synergistic mechanism of water environment governance in Dongting Lake Basin. From the perspective of game theory, this paper will attempt to analyze the factors influencing the construction of the synergistic mechanism of water environment governance in the Dongting Lake Basin, and explore and improve the synergistic mechanism of water environment governance in the Dongting Lake Basin, in order to effectively manage the water environment in the Dongting Lake Basin

\section{Description and Parameter}

\subsection{Behavior analysis of participants}

According to the analysis, there are altogether 8 combination scenarios, as shown in Figure 1:

\subsection{Parameter Setting}

Hypotheses: 1. The governance benefits of local governments are all positive; 2 . The game situation of the remaining two parties is not considered when only one party does not participate in the governance; 3 . The probabilities of $G_{1}, G_{2}$ and $G_{3}$ participating in governance are $x, y$ and $z$ respectively (where $0 \leq x \leq 1,0 \leq y \leq 1,0 \leq z \leq 1$ ), then the probabilities of not participating in governance are $1-x, 1-y$ and $1-z$ respectively.

According to the problem description, set parameters. As shown in: (Note: all the above parameters are positive.)

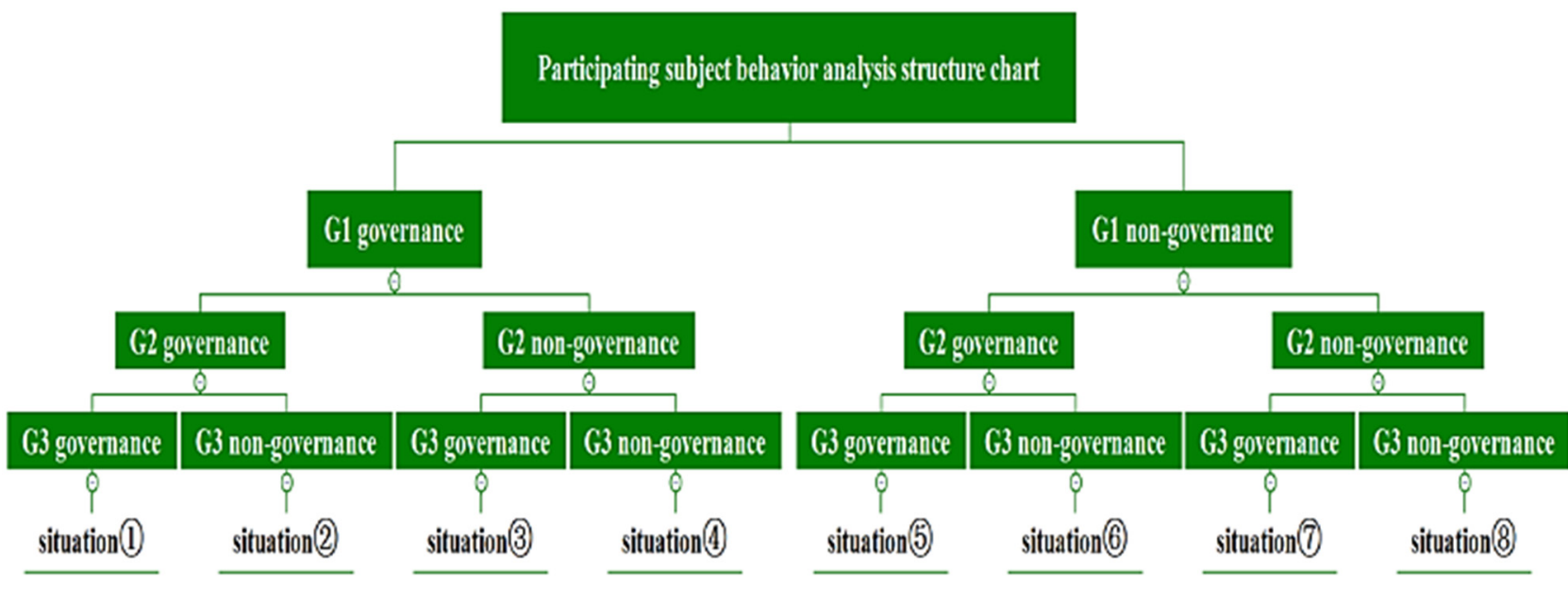

Figure 1: Structure chart

Table 1:Game Parameter Table

\begin{tabular}{|c|c|c|c|c|}
\hline $\mathrm{S} / \mathrm{N}$ & Parameter & $\mathrm{G} 1$ & $\mathrm{G} 2$ & $\mathrm{G} 3$ \\
\hline 1 & governance cost of local government & $\mathrm{C} 1$ & $\mathrm{C} 2$ & $C_{3}$ \\
\hline 2 & $\begin{array}{c}\text { short term economic loss brought by local government } \\
\text { governance }\end{array}$ & $\mathrm{Ls1}$ & $\mathrm{Ls} 2$ & $\mathrm{Ls3}$ \\
\hline 3 & the negative external effect of local government's non- \\
governance & $\mathrm{NE} 1$ & $\mathrm{NE} 2$ & $\mathrm{NE} 3$ \\
\hline 4 & local governments don't manage losses & $\mathrm{L} 1$ & $\mathrm{~L} 2$ & $\mathrm{~L} 3$ \\
\hline 5 & transaction cost of Cooperative Governance & TC1 & TC2 & TC3 \\
\hline
\end{tabular}




\begin{tabular}{|c|r|c|c|c|}
\hline 6 & $\begin{array}{r}\text { local government governance benefits } \\
\text { the positive external effects of local government } \\
\text { governance }\end{array}$ & PE1 & PE2 & PE3 \\
\hline 7 & public benefits brought by local government governance & PB1 & PB2 & PB3 \\
\hline 8 & the ecological compensation given by the superior & EC1 & EC2 & EC2 \\
\hline 10 & penernment & P1 & P2 & P3 \\
\hline 11 & share the externality coefficient & $\alpha 1$ & $\alpha 2$ & $\alpha 3$ \\
\hline 12 & share the public revenue coefficient & $\beta 1$ & $\beta 2$ & $\beta 3$ \\
\hline
\end{tabular}

\section{Game Analysis of Water Environment Governance in Dongting Lake Basin Under Unconstrained Conditions}

\subsection{Replication dynamic evolutionary game analysis}

The replicated dynamic equation is

$$
\begin{gathered}
F(x)=x \times(1-x) \times\left(U_{l g}-U_{l n-g}\right)=x \times(1-x) \times\left(-T C_{l} \times y \times z+E_{l}\right. \\
\left.+\beta_{1} \times P B_{1}-C_{1}-L s_{1}+L_{1}\right)
\end{gathered}
$$

Similarly, the replicative dynamic equations of $G_{2}$ and $G_{3}$ are respectively as follows:

$$
\begin{aligned}
& F(x)=y \times(1-y) \times\left(-T C_{2} \times x \times z+E_{2}+\beta_{2} \times P B_{2}-C_{2}-L s_{2}+L_{2}\right) ; \\
& F(x)=z \times(1-z) \times\left(-T C_{3} \times x \times y+E_{1}+\beta_{3} \times P B_{3}-C_{3}-L s_{3}+L_{3}\right) .
\end{aligned}
$$

Let the value of the replicated dynamic equation be 0 , and since its solution set satisfies, eight special equilibrium points can be obtained as follows: $E_{1}(0,0,0)$, $E_{2}(1,0,0), E_{3}(0,1,0), E_{4}(0,0,1), E_{5}(1,1,0), E_{6}(1,0,1), E_{7}$ $(0,1,1), E_{8}(1,1,1)$. The saddle point $\left(\mathrm{x}^{*}, \mathrm{y}^{*}, \mathrm{z}^{*}\right)$ is

$$
x^{*}=\sqrt{\frac{a_{1} A_{2} A_{3}}{A_{1} a_{2} a_{3}}} ; y^{*}=\sqrt{\frac{A_{1} a_{2} A_{3}}{a_{1} A_{2} a_{3}}} ; z^{*}=\sqrt{\frac{A_{1} A_{2} a_{3}}{a_{1} a_{2} A_{3}}} .
$$

Where $A_{1}=E_{1}+\beta_{1} \times P B_{1}-C_{1}-L s_{1}+$ $L_{1}, A_{2}=E_{2}+\beta_{2} \times P B_{2}-C_{2}-L s_{2}+L_{2}, A_{3}=$ $E_{1}+\beta_{3} \times P B_{3}-C_{3}-L s_{3}+L_{3}, a_{1}=T C_{1}, a_{2}=T C_{2}, a_{3}=T C_{3}$

\subsection{Model analysis}

According to Friedman's criterion method of stable equilibrium point, it can be obtained by local stability analysis of Jacobian matrix. The Jacobian matrix of the system is:

$$
J=\left(\begin{array}{ccc}
(1-2 x)\left(-a_{1} y z+A_{1}\right) & -a_{1} z x(1-x) & -a_{1} y x(1-x) \\
-a_{2} z y(1-y) & (1-2 y)\left(-a_{2} x z+A_{2}\right) & -a_{2} x y(1-y) \\
-a_{3} y z(1-z) & -a_{3} x z(1-z) & (1-2 z)\left(-a_{3} x y+A_{3}\right)
\end{array}\right)
$$

Table 2: Analysis of the Characteristic Root of Governance Game under Unconstrained Condition

\begin{tabular}{l|l|c|c}
$\mathrm{S} / \mathrm{N}$ & Equilibrium & $\begin{array}{c}\text { Characteristics of the } \\
\text { root }\end{array}$ & Result
\end{tabular}

\begin{tabular}{|l|c|c|c|}
\hline 1 & $(0,0,0)$ & $\mathrm{A}_{1}, \mathrm{~A}_{2}, \mathrm{~A}_{3}$ & Unstable \\
\hline 2 & $(1,0,0)$ & $-\mathrm{A}_{1}, \mathrm{~A}_{2}, \mathrm{~A}_{3}$ & Unstable \\
\hline 3 & $(0,1,0)$ & $\mathrm{A}_{1},-\mathrm{A}_{2}, \mathrm{~A}_{3}$ & Unstable \\
\hline 4 & $(0,0,1)$ & $\mathrm{A}_{1}, \mathrm{~A}_{2},-\mathrm{A}_{3}$ & Unstable \\
\hline 5 & $(1,1,0)$ & $-\mathrm{A}_{1},-\mathrm{A}_{2}, \mathrm{~A}_{3}-\mathrm{a}_{3}$ & ESS \\
\hline 6 & $(1,0,1)$ & $-\mathrm{A}_{1}, \mathrm{~A}_{2}-\mathrm{a}_{2},-\mathrm{A}_{3}$ & ESS \\
\hline 7 & $(0,1,1)$ & $\mathrm{A}_{1}-\mathrm{a}_{1},-\mathrm{A}_{2},-\mathrm{A}_{3}$ & ESS \\
\hline 8 & $(1,1,1)$ & $\mathrm{a}_{1}-\mathrm{A}_{1}, \mathrm{a}_{2}-\mathrm{A}_{2}, \mathrm{a}_{3}-\mathrm{A}_{3}$ & Unstable \\
\hline \multicolumn{2}{|l|}{ Since } \\
\hline
\end{tabular}

Since the evolutionary game strategy at the equilibrium point of the game must be a pure strategy, the stability of the replicated dynamic equation can be judged only based on 8 special equilibrium points. When the eigenroot of the replicated dynamic equation is less than 0 , it is the evolutionary equilibrium point of the evolutionary game system.

It can be seen from table 2 that $E_{5}(1,1,0), E_{6}(1,0,1)$ and $E_{7}(0,1,1)$ are evolutionary equilibrium points, that is, "if one party does not govern, two parties govern". The results of the game model show that, under the unconstrained condition, when two parties participate in the governance of the water environment in Dongting Lake Basin, the third party will get a large positive external effect, and the "free rider" phenomenon will occur, which is not conducive to the formation of the situation of three-party cooperative governance.

\section{Game Analysis of Water Environment Governance}

\subsection{Game analysis of payment matrix and replication dynamic}

In the constrained condition, that is, on the basis of the influence of original factors, the higher level government will intervene and give ecological compensation to the government that participates in the governance, and punishment to the government that does not participate in the governance.

Thus, the replicative dynamic equations of, are respectively:

$$
\begin{aligned}
& F(x)=x \cdot(1-x) \cdot\left(-C_{1} y z+E_{1}+E C_{1}+\beta_{1} \cdot P B_{1}-C_{1}-L_{1}+L_{1}+P_{1}\right) \\
& F(y)=y \cdot(1-y) \cdot\left(-C_{2} x_{2}+E_{2}+E_{2}+\beta_{2} \cdot P B_{2}-C_{2}-L_{2}+L_{2}+P_{2}\right) \\
& F(z)=z \cdot(1-z) \cdot\left(-T_{3} x y+E_{3}+E C_{3}+\beta_{3} \cdot P B_{3}-C_{3}-L_{3}+L_{3}+P_{3}\right)
\end{aligned}
$$


Eight special equilibrium points of the dynamic equation system are obtained, which are $E_{I}{ }^{l}(0,0,0)$, $E_{2}{ }^{l}(1,0,0), E_{3}{ }^{l}(0,0,1), E_{4}{ }^{l}(1,1,0,1), E_{5}{ }^{l}(1,0,1), E_{6}{ }^{l}(0,1,1)$, $E_{7}^{l}(1,1,1)$, and $E_{8}^{l}(1,1,1)$.

\subsection{Model Analysis}

Similarly, according to the criterion method of stable equilibrium point proposed by Friedman, it is the point that makes the replicated dynamic equation less than 0 . Among them,

$$
\begin{aligned}
& \mathrm{B}_{1}=\mathrm{E}_{1}+\mathrm{EC}_{1}+\beta_{1} \cdot \mathrm{PB}_{1}-\mathrm{C}_{1}-\mathrm{Ls}_{1}+\mathrm{L}_{1}+\mathrm{P}_{1} \\
& \mathrm{~B}_{1}=\mathrm{E}_{2}+\mathrm{EC}_{2}+\beta_{2} \cdot \mathrm{PB}_{2}-\mathrm{C}_{2}-\mathrm{Ls}_{2}+\mathrm{L}_{2}+\mathrm{P}_{2} \\
& \mathrm{~B}_{1}=\mathrm{E}_{3}+\mathrm{EC}_{3}+\beta_{3} \cdot \mathrm{PB}_{3}-\mathrm{C}_{3}-\mathrm{Ls}_{3}+\mathrm{L}_{3}+\mathrm{P}_{3}
\end{aligned}
$$

Table. 3 Analysis of Characteristic Roots of Governance Game under Constrained Conditions

\begin{tabular}{|c|c|c|c|}
\hline $\mathrm{S} / \mathrm{N}$ & Equilibrium & $\begin{array}{c}\text { Characteristics } \\
\text { of the root }\end{array}$ & Result \\
\hline 1 & $(0,0,0)$ & $\mathrm{B}_{1}, \mathrm{~B}_{2}, \mathrm{~B}_{3}$ & Unstable \\
\hline 2 & $(1,0,0)$ & $-\mathrm{B}_{1}, \mathrm{~B}_{2}, \mathrm{~B}_{3}$ & Unstable \\
\hline 3 & $(0,1,0)$ & $\mathrm{B}_{1},-\mathrm{B}_{2},-\mathrm{B}_{3}$ & Unstable \\
\hline 4 & $(0,0,1)$ & $\mathrm{B}_{1}, \mathrm{~B}_{2},-\mathrm{B}_{3}$ & Unstable \\
\hline 5 & $(1,1,0)$ & $-\mathrm{B}_{1}, \mathrm{~B}_{2}, \mathrm{~B}_{3}-\mathrm{a}_{3}$ & Unstable \\
\hline 6 & $(1,0,1)$ & $-\mathrm{B}_{1}, \mathrm{~B}_{2}-\mathrm{a}_{2}, \mathrm{~B}_{3}$ & Unstable \\
\hline 7 & $(0,1,1)$ & $\mathrm{B}_{1}-\mathrm{a}_{1},-\mathrm{B}_{2},-\mathrm{B}_{3}$ & Unstable \\
\hline 8 & $(1,1,1)$ & $\begin{array}{c}\mathrm{A}_{1}-\mathrm{B}_{1}, \mathrm{a}_{2}-\mathrm{B}_{2}, \\
\mathrm{a}_{3}-\mathrm{B}_{3}\end{array}$ & ESS \\
\hline
\end{tabular}

As shown in 3 it is easy to find that under the constraint conditions $E_{8}{ }^{l}(1,1,1)$ is the evolutionary equilibrium point of the replicated dynamic equation, corresponding to "three-party governance". The results show that the evolutionary game system of water environment governance in Dongting Lake Basin will converge along the asymptote of the saddle point in the direction of $E_{8}{ }^{l}$ $(1,1,1)$ under the constraints of the superior government. Based on the superior government and the long-term perspective, the optimal strategy for water environment governance of Dongting Lake Basin is $E_{8}{ }^{l}(1,1,1)$.

\section{SIMULATION ANALYSIS}

The Matlab software is used to conduct dynamic simulation of the evolution trend of the game system.

\subsection{Variable Assignment}

Combined with the actual situation of local governments in the eastern, western and southern Dongting Lake regions and the analysis of characteristic roots in Tab. 2,3 and Table. , parameters in the model were assigned [12], and $T C_{1}, T C_{2}$ and $T C_{3}$ were all set as $1 . E_{1}, E_{2}$ and $E_{3}$ were $1.5,1.2$ and 0.57 , respectively. $\beta_{1}, \beta_{2}$ and $\beta_{3}$ were $0.5,0.3$ and 0.35 , respectively. $P B_{1}, P B_{2}$ and $P B_{3}$ were $0.4,1$ and 0.8 , respectively. $C_{1}, C_{2}$ and $C_{3}$ were $1,1.06$ and 0.69 , respectively; $L s_{1}, L s_{2}$ and $L s_{3}$ are $1,0.8$ and 0.8 , respectively. $L_{1}, L_{2}$ and $L_{3}$ were $1,0.7$ and 0.75 , respectively. $E C_{1}, E C_{2}$ and $E C_{3}$ are $0.2,0.3$ and 0.4 , respectively. The values of $P_{1}, P_{2}$ and $P_{3}$ are $0.3,0.4$ and 0.6 , respectively. The initial probability $x_{0}, y_{0}$ and $z_{0}$ of the given three parties' participation in governance are $0.5,0.3$ and 0.35 respectively.

\subsection{Simulation water environment governance behavior}

In the absence of superior government constraints, the simulation results of the evolutionary game of the threeparty government are shown in fig. 2 a-d, Fig 2a shows the simulation of the evolutionary game of the three-party government without superior government constraints. As the time cycle progresses, the gradual trend points are $(1,1,0)$. In Fig $2 \mathrm{~b}, z$ finally converges to 0 when $T C=1$. As time progresses, $x$ and $y$ increase continuously and approach to 1 gradually, in which $x$ approaches to 1 earlier than $y$. Further raise $T C$ to 10 , simulate the condition that there is almost no basis for cooperation in the early stage of problem management, and find that the time for $x$ to converge to 1 is slow, $y$ tends to evolve below the initial governance probability in the early stage, and the time for $z$ to approach 0 is faster. In Fig $2 \mathrm{c}, x_{0}, y_{0}$ and $z_{0}$ are adjusted to $0.2,0.1$ and 0.1 respectively. After reducing the initial governance probability, the time for $x$ and $y$ to converge to 1 becomes longer, while the time for $z$ to converge to 0 becomes shorter.

Under the constraint of the superior government, the simulation results of the evolutionary game of the threeparty government are shown in Fig 2a-d, Fig 3 is the scenario simulation of the three-party government evolution game under the constraints of the superior government, which reflects the evolution process of the interaction behavior of the three-party government. The gradual trend points are $(1,1,1)$, and the Nash equilibrium is finally reached. In addition, it is found in fig 3 that some points cluster at $(1,1,0),(1,0,1)$ and $(0,1,1)$, indicating that all the tripartite governments have had short-term cooperative governance behaviors before reaching Nash equilibrium. As shown in fig 3 , the convergence rate of $x$ and $y$ to 1 becomes slower after the reduction of the constraint intensity of the superior government. $z$ converges to 1 under the condition of high constraint intensity, which tends to be high in the early stage and tends to be close to 0 in the later stage, and finally the three-party cooperative governance cannot be achieved. 


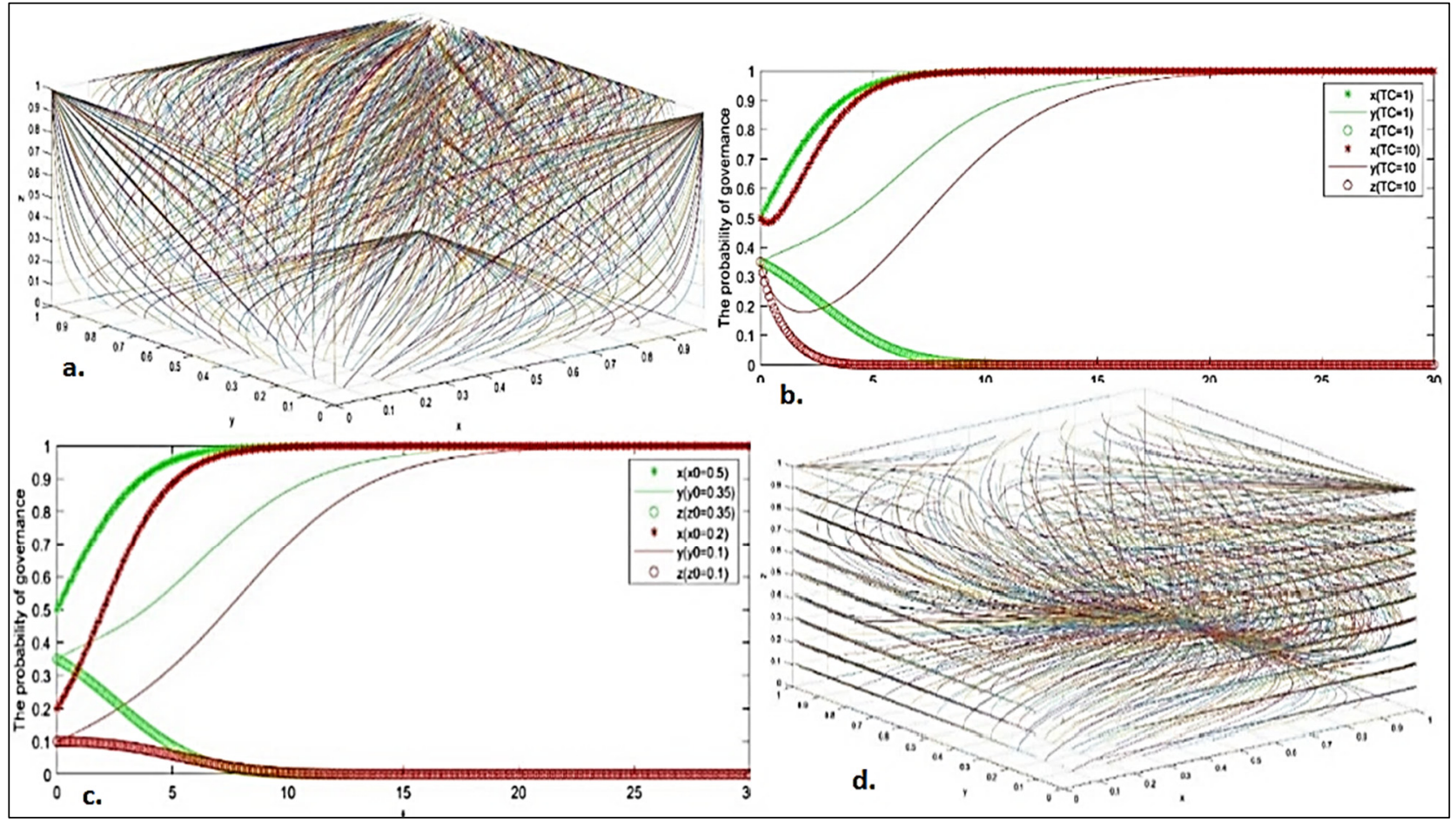

Fig. 2: a. Simulation of tripartite governments without constraints, b. Simulation of tripartite governments after TC change, c. Simulation of tripartite governments after the change of initial governance probability d. Simulation of tripartite governments after the change of superior government's binding force

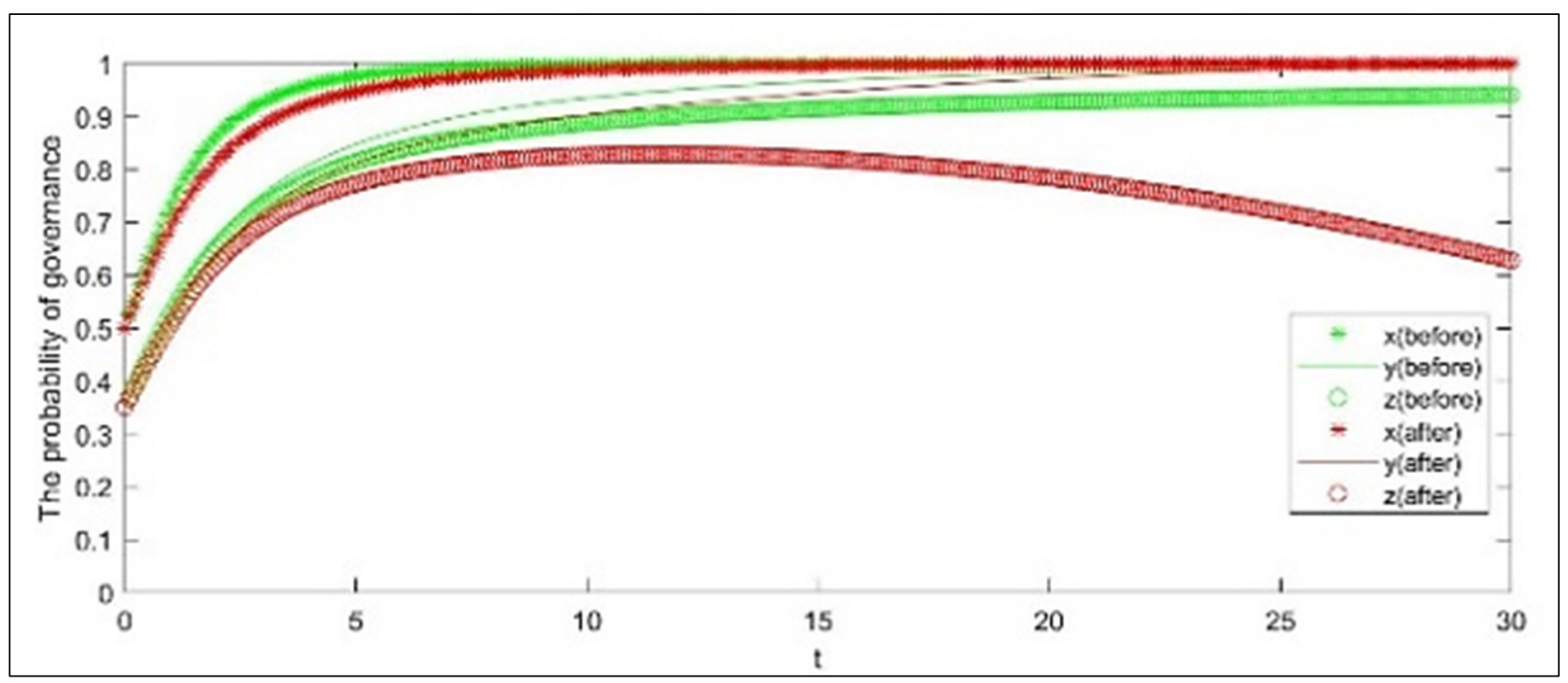

Fig. 3: Simulation of tripartite government under the constraint

\section{RESULTS ANALYSIS AND SUGGESTIONS}

Based on the above analysis, the conclusion is as follows:

(1) For a basin like Dongting Lake with obvious differences and prominent contradictions among different lakes, it is not necessary to limit the traditional upstream and downstream game analysis. Based on the reality and considering the characteristics of the lake region, an appropriate game model can be constructed to make the equilibrium strategy more practical.
(2) With or without constraints, the formulation of strategies of game players is related to governance costs, governance benefits and transaction costs of cooperative governance. In addition, the basis of cooperative governance mechanism and the initial willingness of the subjects to participate in governance have a direct impact on the achievement of the situation of tripartite cooperative governance.

(3) In the absence of constraints, "one party governance, both sides don't governance" of public benefits and positive external effect is small, even if one party governance cost - benefit analysis is positive, to make the management behavior decision, the other two 
party governance is lost is greater than income, unable to reach management synergy mechanism, not governance party on apanage management responsibility implementation also can appear "policy, The negative phenomenon of "there are countermeasures" will eventually lead to "tripartite non-governance" due to the transfer of pollution from the untreated party. And "two party governance, one party is not governance" of public benefits and positive external effects, participants based on their own benefit maximization, will appear "freerider" phenomenon, in the dongting lake, east dongting lake due to the special geographical position most likely to take "free rider" behavior, in the end, no constraint conditions, the evolutionary stable strategy game for the "two party, one party does not control".

(4) Under constraint conditions, the stability strategy of the evolutionary game system converges to "three-party governance". The income difference between players participating in governance and those not participating in governance is positively correlated with the size of $E C$ and $P$ imposed by the superior government. At the same time, compared with the return difference between governance and non-governance of the game subject under the unconstrained condition, the key to the return difference with the involvement of the superior government is the participation of $E C$ and $P$. In addition, when the restraint intensity of the superior government decreases, the tripartite cooperation situation reached in the early stage may degenerate into "two-party governance and one party does not govern" due to the reduced restraint intensity and considerable public benefits and positive external effects generated by the two-party cooperative governance. Therefore, the success of the construction of synergistic mechanism of water environment governance in Dongting Lake mainly depends on the size of $E C$ and $P$ given by the superior government and the durability of the constraints imposed by the superior government. The results show that the government has a certain intrinsic motivation to deal with the cross-regional watershed environmental governance issues, and at the same time, it is obviously affected by external driving factors.

Accelerate the integration process of regional development of Dongting Lake. On the one hand, the integration of regional development will internalize external pollution, promote regional governments to share interests and risks, and strengthen the motivation of internal governance. On the other hand, the promotion of integration of regional development provides the cooperation foundation for regional collaborative governance, reduces the transaction cost of regional collaborative governance cooperation, and promotes the establishment of regional cooperative governance mechanism. First, strengthen regional legal integration [13] The present research will improve the mechanism for joint law enforcement and prevention and control of water environmental pollution in the Dongting Lake Basin. First, the policy plan for emergency joint prevention and control of Dongting Lake Basin shall be formulated and introduced in accordance with the Guiding Opinions on the Establishment of Joint Prevention and Control Mechanism for Emergent Water Pollution Incidents [14-
16] in the Upper and Lower Waterways of Trans provincial Waterways, and the goals, responsibilities and measures of pollution prevention and control of the regional government shall be clearly defined in the plan. Second, the organization system for emergency joint prevention and control in the Dongting Lake Basin shall be improved, which consists of the joint emergency committee for water environment in the Dongting Lake Basin, the special emergency headquarters and the working mechanism for joint prevention and control set up by the regional government to coordinate and guide the water environment management in the Dongting Lake Basin. Third, the system of emergency joint prevention and control in the Dongting Lake Basin should be optimized, and regional emergency joint teams should be set up to realize joint decision-making, information exchange, team coordination and material sharing, so as to form joint management force. Fourth, we should build professional mediators and professional supervision and law enforcement teams, strengthen the selection and training of professional mediators and professional supervision and law enforcement personnel, form professional teams to mediate cross-border disputes, strictly supervise law enforcement, enhance governance capacity and improve governance efficiency, we should innovate data information monitoring methods, make full use of big data and block chain technology to track, collect and analyze local government watershed governance information, and strengthen information supervision. Thirdly, the relevant information communication channels should be unimpeded, the system of regular dialogue and communication and joint meetings should be established, and the consultation channels should be unimpeded.

\section{Acknowledgment}

This research is supported by the National Social Science Foundation of China (No.17CZZ022); Project of Social Science Achievements Evaluation Committee of Hunan Province (No. XSP17YBZZ111); Philosophy and Social Science Foundation of Hunan Province (No.16YBQ058)

\section{References}

1. Yang Mengjie, Yang Kai. Cooperative mechanism for the protection of trans-boundary river water resources from the perspective of game: A case study of Taipu River in the Taihu Lake Basin. J. of Natural Res, 34(06):1232-1244 (2019).

2. Sohail, M.T., Ullah, S., Majeed, M.T. Pakistan management of green transportation and environmental pollution: a nonlinear ARDL analysis. Environl Sci and Poll Res, 1-10, (2021).

3. Mahjouri N, Ardestan M.A game theoretic approach for interbasin water resources allocation considering the water quality issues. Environ. Monit and Assess, 167:527-544 (2011).

4. Li Ning, Wang Lei, et al. Stakeholder decisionmaking behavior of watershed ecological compensation based on game theory. Statis and Dec, 
23 (2017).

5. Hu Zhenhua, Liu Jingyue. Analysis on the balance of benefits of ecological compensation in transboundary watershed based on evolutionary game: A case study of Lijiang River Basin. Economic Geography, 36(06):42-49 (2016).

6. YANG Guangming, SHI Yanjun. Journal of System Simulation, 31(10):2058-2067 (2019).

7. Ding Shejiao. Analysis on the paradox of institutional incentive for river pollution control. Chinese J. of Admin Manag, (02):37-40 (2018).

8. Li Sheng. Research on performance optimization of cross-administrative watershed water pollution control based on institutional analysis. Bulletin of Soil and Water Conservation,35 (2015).

9. Zhang Jun, Zhang Rong. Application of game theory in river water pollution control. Green Economy, 5356 (2006).

10. Lai Ping, Cao Guohua et al. Study on cost allocation of watershed water pollution treatment based on cooperative game. J. of Eco. and $\mathrm{Ru}$ Environ,27 (2011).

11. SHI G M, WANG J N, ZHANG B, et al. Pollution control costs of a transboundary river basin: Empirical tests of the fairness and stability of cost allocation mechanisms using game theory. J. of Environ Manag, 177:145-152 (2016).

12. Li Junjie, Zhang Hong. Evolutionary game and simulation study on air pollution control behavior between local governments. Opera Res and Manag, 28(08):29-33 (2019).

13. Zhang Ruirui. Interregional collaborative governance in the era of high-speed railway: opportunities, challenges and mechanism construction. Sci and Tech Manag Res, (2015).

14. Guidelines on the establishment of a joint prevention and control mechanism for emergent water pollution incidents in the upper and lower reaches of interprovincial basins [EB/OL]. Min. of Water Res (2020).

15. Sohail, M. T., Mahfooz, Y., Azam, K., Yen, Y., Genfu, L., \& Fahad, S. Impacts of urbanization and land cover dynamics on underground water in Islamabad, Pakistan. Des, and water treat, 159, 402-411(2019).

16. Sohail, M. T., Mahfooz, Y., Aftab, R., Yen, Y., Talib, M. A., \& Rasool, A. Water quality and health risk of public drinking water sources: a study of filtration plants installed in Rawalpindi and Islamabad, Pakistan. Des. and water treat., 181, 239-250 (2020). 